\title{
Influence of Pharmaceutical Company Engagement Activities on the Decision to Prescribe: A Pilot Survey of UK Rare Disease Medicine Prescribers
}

\author{
Ravi Jandhyala ${ }^{1,2}$ (1)
}

Published online: 9 January 2020

(c) The Author(s) 2020

\begin{abstract}
Introduction Traditionally, the pharmaceutical industry has used 'promotional personal engagement' activities, which involve interactions between sales forces and prescribers, in order to generate 'sales'—or prescriptions—of their new medicinal product(s). There appears to be now a favouring of 'non-personal engagement' (external information sources or activities existing outside the direct control of the company) and 'non-promotional personal engagement' activities (focused around creating peer-to-peer relationships between prescribers and pharmaceutical physicians).

Objectives The purpose of this study was to examine the influence of non-personal engagement and non-promotional personal engagement activities on the prescribing habits of British healthcare professionals, using the traditional promotional personal engagement activities as a comparator.

Methods A questionnaire was distributed to 122 prescribers (physicians, nurses and pharmacists) working with two selected products for pulmonary arterial hypertension. The participants were asked to rate the influence that the listed activities had on their decision to prescribe each of the two products using a scale of $0-10$, where $0=$ 'no influence' and $10=$ 'most important influence'. Results Of the 122 targeted healthcare professionals who received the questionnaire, 34 (27.9\%) responded within the 2-week time limit ( 24 physicians, 5 nurse prescribers and 5 pharmacists). The findings of the survey had a confidence level of $90 \%$ and a margin of error of $12 \%$, given that 34 of 122 people responded. All proposed activities were scored by the respondents as having some influence on their prescribing. Personal engagement activities are effective for influencing prescribing, but non-promotional personal engagement activities may be more influential than promotional personal engagement activities. Furthermore, non-personal engagement activities may be more effective in influencing prescriptions of a product than either non-promotional or promotional personal engagement activities.

Conclusions All personal engagement activities affect HCP prescribing behaviours; however, they appear to be more influential when performed on a non-promotional basis by representatives of the company's medical department.
\end{abstract}

\section{Introduction}

Drug development is associated with high costs and, following successful regulatory approval of a new medicinal product, pharmaceutical companies must try and recoup

Electronic supplementary material The online version of this article (https://doi.org/10.1007/s40290-019-00323-x) contains supplementary material, which is available to authorized users.

Ravi Jandhyala

ravi@medialis.co.uk

University of Leicester Business School, Leicester, UK

2 Medialis Limited, 13 Horse Fair, Banbury, Oxfordshire OX16 0AH, UK these costs, not only to remain profitable but also to enable subsequent research and development activities. Like many other industries, these companies use a promotional mix - defined as "the specific blend of advertising, public relations, personal selling, sales promotion, and directmarketing tools that the company uses to persuasively communicate customer value and build customer relationships"-to market their new products [1]. However, pharmaceutical companies operate in an arguably more restrictive environment than most other commercial organisations due to additional regulation placed on the marketing and promotion of prescription-only medicines [2-5].

In this industry, studies have shown that sales forces have traditionally had an impact on the decisions of prescribers as "frequent contact with a drug representative 


\section{Key Points}

Pharmaceutical companies employ a range of prescriber engagement activities, including promotional personal, non-promotional personal and non-personal activities.

Prescribers rated non-personal engagement activities as the most influential on their prescribing habits, followed by non-promotional personal engagement activities and, lastly, promotional personal engagement activities.

was significantly associated with a greater willingness to prescribe new drugs and to agree to patients' requests to prescribe a drug that is not clinically indicated, with dissatisfaction with consultations ending in advice only, and with receptiveness to drug advertisements and promotional literature from drug companies" [6]. Furthermore, before effective regulation and compliance legislation was implemented, some studies showed that prescription behaviours were unduly influenced by company-sponsored gifts or inducements [7].

Traditionally, the pharmaceutical industry has used 'promotional personal engagement' activities, which involve interactions between sales forces and prescribers, in order to generate 'sales'-or prescriptions-of their new medicinal product(s) (see Table 1). In this context, the company representatives are not required to have a medical background, but their promotional conversations around any medicinal product(s) are limited as they must be in accordance with the terms of its marketing authorisation and, furthermore, must be consistent with the particulars contained within its summary of product characteristics (clause 3 of the Association of British Pharmaceutical Industry code) [5]. In this regard, various country-specific self-regulatory codes of practice for the pharmaceutical industry require all promotional material and activities, alongside some non-promotional activities, to be approved by a pharmaceutical physician or pharmacist operating in a non-promotional role (clause 14 of the Association of British Pharmaceutical Industry code) [5]. This nonpromotional role is therefore associated with compliance and accountability for good practice in the pharmaceutical industry and, as a consequence, a higher level of trust is generally conferred on their engagements with external stakeholders; this includes their interactions with prescribers, with whom they share a peer-to-peer relationship. It would appear that prescribers' increased appreciation of the influence pharmaceutical companies can exert on their prescription behaviours [8], alongside the implementation of the aforementioned regulations and current trends towards evidence-based prescribing, has meant that the engagement at the pharmaceutical-prescriber interface has evolved in recent times.

As a result of the increasing pressure placed on contemporary prescribers to make evidence-based management decisions, there appears to be a move away from traditional 'promotional personal engagement' activities and a favouring of 'non-personal engagement' and 'non-promotional personal engagement' activities. Indeed, in extreme cases, this evolution has become manifest in some centres banning calls from pharmaceutical sales representatives altogether, in favour of more scientific and less promotional engagement activities [8-10]. 'Non-personal engagement' activities are external information sources or activities existing outside the direct control of the company, but which may act as triggers of prescribing habit modifications (see Table 1). These engagement activities lie outside of the traditional 'promotional personal engagement' framework as they do not involve any interaction between company representatives and prescribers. Some examples of 'non-personal engagement' activities are peer-reviewed publications, official guideline publications, experience exchanges between colleagues and the development of external clinical tools, such as PRODIGY (Prescribing RatiOnally with Decision Support In General Practice StudY). PRODIGY, a piece of software launched in the UK in the 1990s, utilises an underlying knowledge base of clinical information to present primary care providers with advice relevant to their current patient's clinical presentation; the software is still updated and remains in use [11].

As alluded to earlier, pharmaceutical companies can also interact with prescribers through non-promotional representatives, typically members of the company's medical department; these 'non-promotional personal engagement activities' (see Table 1) are becoming increasingly popular with both healthcare practitioners (HCPs) and pharmaceutical companies [12]. They consist of engagements focused around creating the discussed peer-to-peer relationships between prescribers and pharmaceutical physicians. From these relationships, prescribers can obtain scientific information tailored to their needs, as well as being offered the opportunities to participate in real-world evidence (RWE) generating activities and other medical initiatives contained within the company's medical plan for the therapy area. The sales force is precluded from engaging in these discussions due to the inherent promotional nature of their role and the previously discussed regulatory restrictions placed on their interactions with prescribers. Importantly, pharmaceutical physicians do not receive any sales-linked compensation (such as sales target bonuses) and this, alongside their medical background, allows them to discuss a much wider range of topics with prescribers, including off-label product use (albeit in a reactive setting) and those previously mentioned around RWE generation. Although this type of activity has no inherent promotional purpose, it is possible 
Table 1 Summary of the promotional personal engagement activities, non-personal engagement activities, and non-promotional personal engagement activities included within the study questionnaire. The table provides a sales activity alongside a brief description of what it entails

\begin{tabular}{|c|c|}
\hline Activity & Description \\
\hline \multicolumn{2}{|c|}{ Promotional personal engagement activities } \\
\hline Face-to-face promotional meeting & The salesperson delivers a presentation to a group of customers in the same room \\
\hline Individual promotional meeting & The salesperson delivers a pre-approved presentation to a single customer on a 1:1 basis \\
\hline Online promotional meeting & $\begin{array}{l}\text { The salesperson delivers a presentation over the internet via web meetings. The speaker and audience are } \\
\text { at different locations }\end{array}$ \\
\hline Paid peer engagement & $\begin{array}{l}\text { KOLs are engaged through personal selling and advocacy development conducted by a member of the } \\
\text { sales team. KOLs will then present company data to their peers }\end{array}$ \\
\hline Sales calls & $\begin{array}{l}\text { A short meeting, without a formal presentation, to maintain the customer relationship. Explores product } \\
\text { adoption, performance and obstacles preventing adoption and use of the product }\end{array}$ \\
\hline Congress attendance sponsorship & $\begin{array}{l}\text { Selected KOLs will be sponsored to attend relevant congress and symposia. Involves personal engagement } \\
\text { and relationship management }\end{array}$ \\
\hline $\begin{array}{l}\text { Promotional stands and industry } \\
\text { satellite symposia }\end{array}$ & $\begin{array}{l}\text { 'Trade show' engagement, containing a large promotional stand detailing product information. May also } \\
\text { involve sponsorship of a satellite symposium running alongside the main conference agenda where a } \\
\text { company can discuss products, therapeutic area or similar related subjects }\end{array}$ \\
\hline \multicolumn{2}{|c|}{ Non-promotional personal engagement activities } \\
\hline $\begin{array}{l}\text { Industry physician presentation } \\
\text { meeting }\end{array}$ & $\begin{array}{l}\text { Similar to the face-to-face promotional meeting, the industry physician presents an approved presentation } \\
\text { generally containing data surrounding the product }\end{array}$ \\
\hline $\begin{array}{l}\text { Individual visits from the industry } \\
\text { physician }\end{array}$ & $\begin{array}{l}\text { A mirror of the individual promotional meeting, their content may differ as the industry physician is per- } \\
\text { mitted to discuss medical matters that the sales team is not }\end{array}$ \\
\hline Advisory board meetings & $\begin{array}{l}\text { Specific meeting of paid KOLs, typically convened to answer a specific non-promotional question from } \\
\text { the pharmaceutical company. Engagement with KOLs is solely conducted by the medical department } \\
\text { and firewalled from the commercial team to preserve the non-promotional nature of the meeting }\end{array}$ \\
\hline Scientific meetings & $\begin{array}{l}\text { Non-promotional equivalent of the industry satellite symposium; regulators preclude any involvement of } \\
\text { the sales/commercial teams in these meetings. Furthermore, no reference to product branding is permit- } \\
\text { ted (medicines must be referred to by non-promotional, generic names) and the content is expected to be } \\
\text { scientifically robust and unbiased }\end{array}$ \\
\hline Preceptorships & $\begin{array}{l}\text { Company medical departments arrange and fund the visit of hospital HCPs to other teams working within } \\
\text { the same therapy area but in different regions throughout the world }\end{array}$ \\
\hline $\begin{array}{l}\text { Supporting investigator-led studies } \\
\text { or meetings/symposium }\end{array}$ & $\begin{array}{l}\text { These activities, undertaken solely by the medical departments of pharmaceutical companies, are covered } \\
\text { by stringent stipulations in the ABPI codes of practice. Transfers of monies should in no way constitute } \\
\text { an 'inducement to prescribe' and therefore must be completely devoid of any explicit or implicit associa- } \\
\text { tion with product use }\end{array}$ \\
\hline \multicolumn{2}{|l|}{ Non-personal engagement activities } \\
\hline Recommendations from colleagues & $\begin{array}{l}\text { HCPs regularly attend congresses and form practice communities to further their professional education. } \\
\text { During these meetings, informal communications and information exchanges occur that may influence } \\
\text { the decision to prescribe a certain treatment }\end{array}$ \\
\hline National guidelines & $\begin{array}{l}\text { First intention care recommendations from independent formal bodies and/or external stakeholders } \\
\text { charged with the responsibility of reviewing different products and services, i.e. the NICE in the UK } \\
\text { actively reviews all new technologies and provides recommendations based on published evidence and } \\
\text { internal health economic modelling activities }\end{array}$ \\
\hline Peer-review publications & $\begin{array}{l}\text { Articles relating to the product of interest that are published in peer-reviewed journals. Speciality journals } \\
\text { exist to provide HCPs with the latest evidence supporting treatments in a specific field of expertise, and } \\
\text { the peer-review process ensures only quality research is published }\end{array}$ \\
\hline
\end{tabular}

$H C P s$ healthcare professionals, KOLs key opinion leaders, ABPI Association of the British Pharmaceutical Industry, NICE National Institute for Health and Care Excellence

that the interactions between pharmaceutical physicians and prescribers may have an added value to both parties and may indirectly influence prescribing behaviours [8].

In this study, we propose to examine the influence of nonpersonal engagement and non-promotional personal engagement activities on prescribing habits, using the traditional promotional personal engagement activities as a comparator.

\section{Methods}

This study investigated activities that may influence UK prescribers (doctors, nurses and pharmacists) using an internetbased questionnaire. The activities that may influence their prescription behaviours were classified into three groups: (1) promotional personal engagement; (2) non-personal 
engagement; and (3) non-promotional personal engagement (detailed lists of the explored activities and their definitions are provided in Table 1).

\subsection{Participants}

In order to approach all HCPs in one therapy area, all UK prescribers working in the highly specialised therapy area of pulmonary arterial hypertension (PAH) were contacted and asked to complete the questionnaire. Respondents were offered a small remuneration of $£ 20$ as an incentive to complete the questionnaire.

\subsection{Questionnaire Design}

The participants self-reported the influence of the three categories of activities on their prescribing of two drugs approved for use in PAH - ambrisentan (Volibris ${ }^{\circledR}$; Glaxo Group Ltd, Brentford, UK) and epoprostenol $0.5 \mathrm{mg}$ (Flolan ${ }^{\circledR}$; Glaxo Group Ltd). Ambrisentan, an oral tablet used to treat milder cases of PAH, was approved by the European Medicines Agency (EMA) in 2008 for the treatment of PAH. Epoprostenol, approved for use in 1995 by the US FDA and in 2001 by the EMA for the treatment of more severe PAH, has to be administered using an intravenous infusion $[13,14]$. Respondents were asked to rate what influence various personal (either promotional or non-promotional) and non-personal activities had on their prescribing habits for these two drugs using a scale of $0-10$, where $0=$ 'no impact at all on prescription of the product' and $10=$ 'the most important factor in influencing prescribing of the product'. Table 2 lists all questions included in the questionnaire. The responses for the two products were captured in parallel columns to allow respondents to post answers in relation to each other (see Electronic Supplementary Table 1).

\subsection{Questionnaire Implementation and Data Collection}

The target HCPs were identified from a list of physicians, nurses and pharmacists held by GlaxoSmithKline, the manufacturer of both products included for reference in the questionnaire. The respondents were given a period of 2 weeks to complete the questionnaire, after which the database was locked, and the data sent for statistical review.

The database was monitored by Kyeesha Ltd, Streatham, UK, and a de-identified Microsoft Excel spreadsheet
Table 2 Questionnaire assessing the influence of various influence activities

Please select the number that indicates the impact the following activities have had on your prescribing of the following products, where $0=$ 'no impact at all' and $10=$ 'the most important factor'

Promotional personal influence activities

Promotional meetings: face-to-face

Promotional meetings: online

Promotional meetings: where you are paid to present

Calls from sales representatives

Presentations from sales representatives

Congresses: sponsorship for you to attend

Congresses: industry symposia

Congresses: promotional stand

Non-promotional personal influence activities

1:1 visit from industry physician

Meetings where industry physician presents data

Advisory boards

Scientific meetings

Preceptorships

Supporting investigator-initiated studies in your centre

Supporting your meetings with educational grants

Non-personal influence activities

Recommendations from colleagues

National Screening Committee guidelines

Medical literature and published studies

(Microsoft Corporation, Redmond, WA, USA) was forwarded to the principal investigator for statistical review.

\subsection{Statistical Analysis}

The mean influence scores were calculated for the individual types of activity, as well as for the three overall categories of activities. Non-promotional personal influencing activities and non-personal influencing activities were compared with promotional personal influencing activities using Student's paired $t$ test; differences between all three groups were assessed using Tukey's test, a singlestep multiple comparison and significance test. Tukey's test was also employed to find the individual engagement activity mean values that are significantly different from each other by identifying any difference between two means that is greater than the expected standard error. Any differences were used to compile 'groups' of activities (Figs. 1a-c; groups A-E), wherein each group contained no intragroup differences but significant differences between groups were observed. 
Fig. 1 Comparisons of mean influence scores for all selling activities. a Influence of activities for ambrisentan and epoprostenol combined $(n=68)$; $\mathbf{b}$ influence of activities for ambrisentan $(n=34)$; c influence of activities for epoprostenol $(n=34)$. Groups were determined using Tukey's test. The mean influence score of each activity within a specific group were not statistically significantly different but were statistically significantly different for between-group comparisons

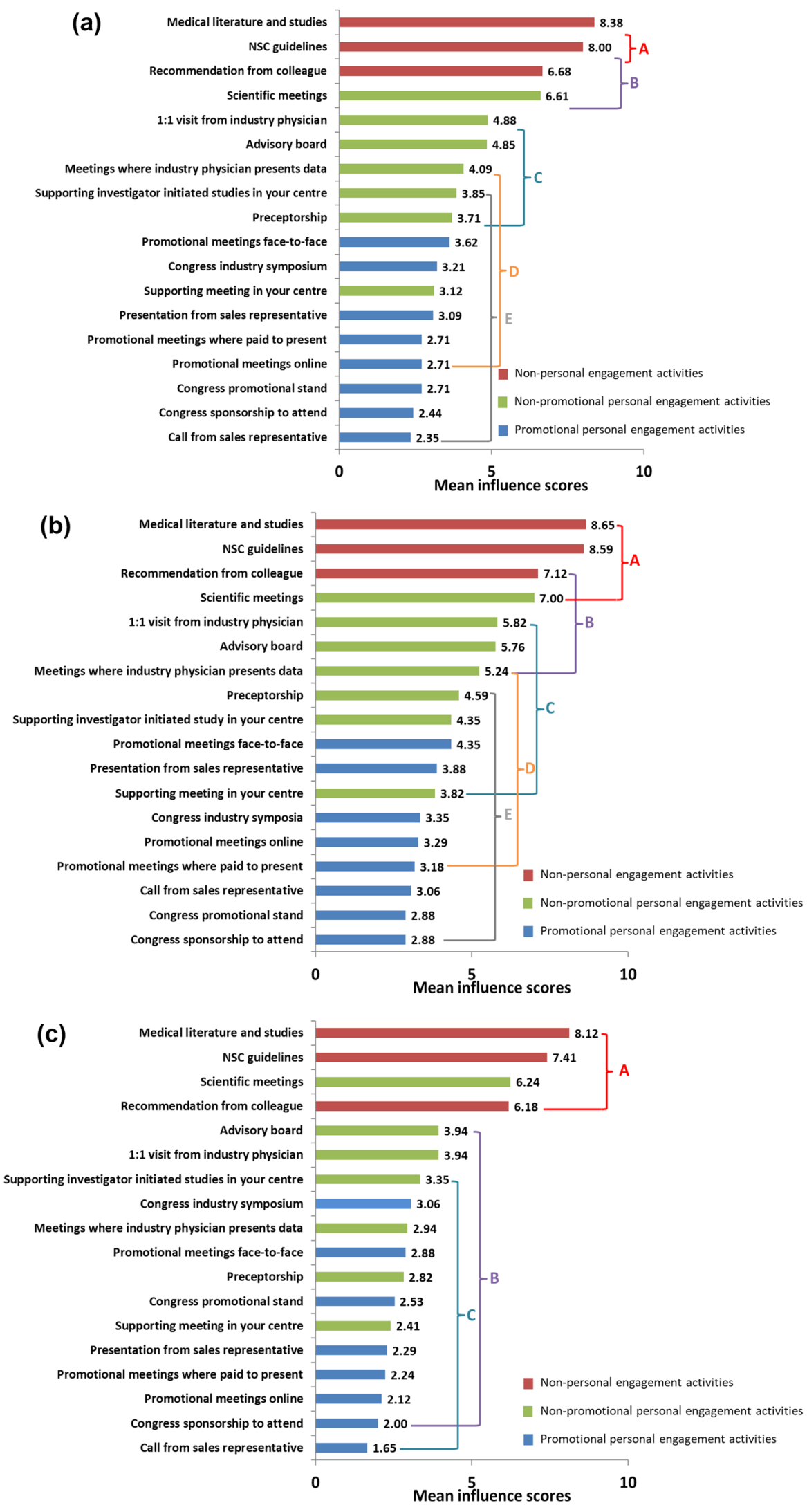




\section{Results}

\subsection{Survey Respondents}

Of the 122 targeted healthcare professionals who received the questionnaire, 34 (27.9\%) responded within the 2-week time limit ( 24 physicians, 5 nurse prescribers, 5 pharmacists). The findings of the survey have a confidence level of $90 \%$ and a margin of error of $12 \%$, given that 34 of 122 people responded [15].

\subsection{Different Types of Activities Influencing Prescription Behaviours}

\subsubsection{Personal versus Non-Personal Engagement Activities}

The combined total mean influence scores for the personal engagement activities were significantly lower than the combined total engagement activities mean score for nonpersonal influencing activities (3.6 vs. 7.7; $p<0.001$ [Student's $t$-test]).

\subsubsection{Promotional versus Non-Promotional Personal Engagement Activities}

The combined total mean scores for the influence of promotional engagement activities was significantly lower than the combined total mean score for the influence of nonpromotional engagement activities [2.85 vs. $4.45 ; p<0.001$ (Student's $t$ test)].

\subsubsection{Comparison between the Three Activity Categories}

The combined total mean scores for the influence of each of the three types of engagement activities were significantly different between all types of activities $[p<0.05$ for all (Tukey's test)].

\subsection{Relative Influence of Personal Activities}

All types of activities were scored by the respondents as having some influence on prescriptions, i.e. the mean influence scores for each activity were greater than zero (Fig. 1). For the combined analysis of both ambrisentan and epoprostenol, 'Medical Literature and Studies' and 'NSC Guidelines' were significantly more influential than all other activities, with mean scores of 8.38 and 8.00, respectively, whereas 'Calls from Sales Representative' were least influential, with a mean score of 2.35 (Fig. 1a). There were differences in how respondents rated the influence of activities depending on which drug the activity was being referred to. Overall, all activities were rated to have a greater influence on the newer drug, ambrisentan, with a large overlap in groupings for promotional and non-promotional personal influencing activities (Fig. 1b) compared with epoprostenol, which had no overlap in groupings for promotional and nonpromotional personal influencing activities (Fig. 1c).

In considering both products together and the impact of the various individual activities side by side, there was very little to differentiate the two products other than the Tukey groupings. The only significant difference noted between the two products was with the preceptorship activity, a nonpromotional visit organised by the manufacturer for a team from a centre in one country to visit a centre in another country; the impact of this activity was statistically greater with ambrisentan than epoprostenol. This may be attributable to the fact that ambrisentan is a new product and requires more guidance than the older epoprostenol. The opportunity for physicians to visit another hospital using the new product and to gain peer-to-peer advice in this setting may account for the difference with epoprostenol, which is a product they have already had more than a decade of experience with.

\section{Discussion}

This study investigated the influence of personal and nonpersonal engagement activities as rated by HCP prescribers (physicians, nurses and pharmacists) who work within the therapy area of PAH in the UK.

The results of this survey suggest that promotional personal engagement activities may still have a place within the pharmaceutical promotional mix as their influence on prescribing habits was rated, on average, above zero. However, although it is their principal purpose, promotional personal engagement activities had a lower influence on the behaviour of prescribers than non-personal and non-promotional personal engagement activities (Fig. 1).

In general, prescribers rated non-promotional personal engagement activities as having a much greater impact on their prescribing habits than promotional personal engagements; this is in keeping with the population-level shifts towards evidence-based prescription habits. The finding that the influence of these activities on prescribing habits was rated above the influence of the traditional promotional personal engagements does raise a series of interesting questions. For example, as the medical and sales departments of pharmaceutical companies are both approaching the same group of people, and the medical department can engage in a much wider-ranging discussion around the company's medicines (and the RWE-generating medical plan in general), the higher influence of their non-promotional engagements calls into question the contemporary utility of a dedicated sales force. Furthermore, when considering a wider view of the 
pharmaceutical industry, peer-to-peer evidence-based discussions around new medicines may be seen as a more trustworthy source of information than that provided by a sales representative; this is particularly important for an industry whose reputation may have been tarnished in the eyes of both HCPs and the general population alike in recent times. It may also be beneficial that the pharmaceutical physicians of the company medical department are likely to have been involved in the majority of the product lifecycle, from initial research and development, through clinical studies, to RWE-generating and phase IV studies; the robust and constantly developing scientific knowledge of these physicians may be of significant utility throughout the commercial life of the product.

It was observed that non-promotional personal influence was higher for the newer drug in the survey. This could reflect the reality that during the early stages of the product lifecycle, robust, high-quality external sources of information might be scarce, making the company physicians the key point of contact for the provision of evidence-based support in their prescription decisions prior to the development of a wider experience with the new product. This would apply even more in the context of rare diseases, where many medicines are repurposed and/or used off-label; the in-depth scientific product knowledge of pharmaceutical physicians, including in areas such as the product's mechanisms of action, would be invaluable in these situations [16]. However, the deliberate use of non-promotional activities with marketing goals does exist, raising intricate ethical questions about the role of key opinion leaders and potential conflicts of interest throughout the lifecycle of a drug $[6,8]$.

Perhaps not surprisingly, non-personal engagement activities appeared to have the largest impact on prescribing behaviours, highlighting the importance of easily accessible, high-quality external sources of information to prescribers. While these activities are, by nature, perceived to be external to the pharmaceutical company, the results of this study highlight the need for pharmaceutical companies to be aware of the external factors and discussions that may be ongoing around their products. This is particularly important in an age of instantaneous information distribution and communication, increasing individual involvement in their care providence and social media, all of which can have a substantial impact on uptake and utilisation of a medicinal product. Furthermore, the judicious use of the medical department, alongside panels of engaged HCPs, in the development, implementation and delivery of an RWE medical plan, culminating in a portfolio of key publications, will leverage this observed heightened influence of peer-reviewed articles in decision making. This tactic would exploit the synergy between non-promotional personal engagement and non-personal engagement.

This study has a number of limitations. The sample population was not chosen at random and, as such, the sample may not be representative of the whole population being studied; this undermines the ability to make generalisations from the collected data. Furthermore, as there were relatively few participants, it was not statistically meaningful to assess the impact of each of the activities by subgroups of customers (i.e. physician, nurse, pharmacist), which would have provided valuable information; repeating the survey with a larger target population would be of significant interest. However, the benefits lie in the ease of implementation and low cost of the survey approach, meaning that a subsequent study incorporating more participants could be quickly and easily conducted.

The list of activities provided for rating is an exhaustive list of personal and non-personal activities and therefore satisfies the content validity of the questionnaire. However, the central question relates to an inherently abstract, subjective assessment on the part of the subject; this is not easily validated. Nonetheless, influence on decision making is important when considering HCP prescription habits. In addition, personal influencing and prescription behaviours are a multifactorial phenomenon, meaning it is almost impossible to model exhaustively; responsiveness to personal influencing can vary by person, country, industry and product, among other variables, for example. However, generating an understanding of the average effects of different activities or activity types will be invaluable in order to increase the awareness of prescribers regarding the effects of different activities on their own prescription behaviours.

\section{Conclusions}

To summarise, all personal engagement activities affect $\mathrm{HCP}$ prescribing behaviours; however, they appear to be more influential when performed on a non-promotional basis by representatives of the company's medical department. Perhaps counter-intuitively, activities with an explicit promotional purpose were seen to be less effective at influencing prescribing than non-promotional activities. However, nonpersonal engagement activities may be a more important driver than any personal engagement activities, highlighting the importance of high-quality clinical and RWE research, timely publication of key results and product-related information, and promotion of communication and experience sharing between prescribers. However, further research is required in this area, for example to determine the relative influence of pharmaceutical-funded publications compared with publications funded by other sources.

Acknowledgements Ravi Jandhyala would like to thank Adrian Mills for his guidance during this project and Lovemore Gakava for his support in the statistical analysis. This project was part of an MBA thesis 
submitted by the author (RJ). Database management was performed by Kyeesha Ltd, Streatham, UK, and funded by GlaxoSmithKline. Editorial and medical writing support for manuscript preparation was provided by Alexander T. Hardy, PhD (Medialis Ltd), Cecile Limousin (Medialis Ltd) and Celia J. Parkyn, PhD (funded by Medialis Limited).

\section{Compliance with Ethical Standards}

Funding The research received an educational grant from GlaxoSmithKline. The open access fee was paid by Medialis Ltd.

Conflicts of interest Ravi Jandhyala has previously worked as a pharmaceutical physician in the PAH therapy area at GlaxoSmithKline and is currently the managing director of Medialis Ltd, a medical affairs consultancy offering paid consultancy services surrounding clinical and post-authorisation research.

Open Access This article is licensed under a Creative Commons Attribution-NonCommercial 4.0 International License, which permits any non-commercial use, sharing, adaptation, distribution and reproduction in any medium or format, as long as you give appropriate credit to the original author(s) and the source, provide a link to the Creative Commons licence, and indicate if changes were made. The images or other third party material in this article are included in the article's Creative Commons licence, unless indicated otherwise in a credit line to the material. If material is not included in the article's Creative Commons licence and your intended use is not permitted by statutory regulation or exceeds the permitted use, you will need to obtain permission directly from the copyright holder. To view a copy of this licence, visit http://creativecommons.org/licenses/by-nc/4.0/.

\section{References}

1. Kotler P, Armstrong G. Principles of marketing. 14th ed. Upper Saddle River: Prentice Hall; 2011.

2. Silverman E. Everything you need to know about the Sunshine Act. BMJ. 2013;347:f4704. https://doi.org/10.1136/bmj.f4704.

3. Fabbri A, Santos Ancel la, Mezinska S, Mulinari S, Mintzes B. Sunshine policies and murky shadows in europe: disclosure of pharmaceutical industry payments to health professionals in nine european countries. Int J Health Policy Manag 2018;7:504-9. https://doi.org/10.15171/ijhpm.2018.20.
4. European Federation of Pharmaceutical Industries and Associations (EFPIA). EFPIA code on the promotion of prescriptiononly medicine to, and interactions with, healthcare professionals. EFPIA; 2014.

5. Prescription Medicines Code of Practice Authority (PMCPA). Code of practice for the pharmaceutical industry. PMCPA; 2016.

6. Watkins C. Characteristics of general practitioners who frequently see drug industry representatives: national cross sectional study. BMJ. 2003;326:1178-9. https://doi.org/10.1136/ bmj.326.7400.1178.

7. Orlowski JP, Wateska L. The effects of pharmaceutical firm enticements on physician prescribing patterns. Chest. 1992;102:270-3. https://doi.org/10.1378/chest.102.1.270.

8. Jackson T. Are you being duped? BMJ. 2001;322:1312.

9. Harris G. Pharmaceutical representatives do influence physician behaviour. Fam Pract. 2009;26:169-70. https://doi.org/10.1093/ fampra/cmp033.

10. Huddle TS. Drug reps and the academic medical center: a case for management rather than prohibition. Perspect Biol Med. 2008;51:251-60. https://doi.org/10.1353/pbm.0.0012.

11. Purves IN. PRODIGY: implementing clinical guidance using computers. Br J Gen Pract. 1998;48:1552.

12. Setia S, Ryan NJ, Nair PS, Ching E, Subramaniam K. Evolving role of pharmaceutical physicians in medical evidence and education. Adv Med Educ Pract. 2018;9:777-90. https://doi. org/10.2147/AMEP.S175683.

13. Barst RJ, Rubin LJ, Long WA, McGoon MD, Rich S, Badesch $\mathrm{DB}$, et al. A comparison of continuous intravenous epoprostenol (prostacyclin) with conventional therapy for primary pulmonary hypertension. N Eng1 J Med. 1996;334:296-301. https://doi. org/10.1056/NEJM199602013340504.

14. Rubin LJ, Mendoza J, Hood M, McGoon M, Barst R, Williams $\mathrm{WB}$, et al. Treatment of primary pulmonary hypertension with continuous intravenous prostacyclin (epoprostenol). Results of a randomized trial. Ann Intern Med 1990;112:485-91. https://doi. org/10.7326/0003-4819-112-7-485.

15. Penwarden R. Response rate statistics for online surveys: what numbers should you be aiming for? FluidSurveys 2014. http:// fluidsurveys.com/university/response-rate-statistics-online-surve ys-aiming/. Accessed 11 Dec 2019.

16. Dooms M, Cassiman D, Simoens S. Off-label use of orphan medicinal products: a Belgian qualitative study. Orphanet J Rare Dis. 2016;11(1):144. https://doi.org/10.1186/s13023-016-0507-y. 